\title{
Parasomnias and antidepressant therapy: a review of the literature
}

\author{
Lara Kierlin ${ }^{1,2}$ and Michael R. Littner ${ }^{1,2} *$ \\ ${ }^{1}$ David Geffen School of Medicine at University of California Los Angeles, Los Angeles, CA, USA \\ 2 Pulmonary, Critical Care and Sleep Medicine, VA Greater Los Angeles Healthcare System, Los Angeles, CA, USA
}

Edited by:

Ruth Benca, University of

Wisconsin - Madison School of

Medicine, USA

Reviewed by:

Ruth Benca, University of

Wisconsin - Madison School of

Medicine, USA

David Plante, University of Wisconsin, USA

\section{*Correspondence:}

Michael R. Littner, 10736 Des Moines

Avenue, Porter Ranch, Los Angeles,

CA 91326, USA.

e-mail:mlittner@ucla.edu
There exists a varying level of evidence linking the use of antidepressant medication to the parasomnias, ranging from larger, more comprehensive studies in the area of REM sleep behavior disorder to primarily case reports in the NREM parasomnias. As such, practice guidelines are lacking regarding specific direction to the clinician who may be faced with a patient who has developed a parasomnia that appears to be temporally related to use of an antidepressant. In general, knowledge of the mechanisms of action of the medications, particularly with regard to the impact on sleep architecture, can provide some guidance. There is a potential for selective serotonin reuptake inhibitors, tricyclic antidepressants, and serotonin-norepinephrine reuptake inhibitors to suppress REM, as well as the anticholinergic properties of the individual drugs to further disturb normal sleep architecture.

Keywords: parasomnias, REM sleep behavior disorder, non-REM parasomnias, selective serotonin reuptake inhibitors, depression

\section{INTRODUCTION}

Parasomnias are a diagnostic grouping of sleep disorders that include abnormal sleep-related behaviors, dreams, or autonomic changes that manifest during transitions from wakefulness to sleep, or within transitions between sleep stages. Parasomnia sufferers may complain of unwanted interruptions from sleep, injury to themselves, or to their bed partner during periods of motor activation, and dysphoria relating to the burden of shouldering these negative sequelae. The International Classification of Sleep Disorders categorizes parasomnias into (1) disorders of arousal from NREM (non-rapid eye movement) sleep - these include somnambulism, confusional arousals, and sleep terrors; (2) disorders of REM (rapid eye movement) sleep - these include REM sleep behavior disorder (RBD), nightmares, and recurrent isolated sleep paralysis; and (3) other parasomnias - these include sleep-related dissociative disorder, sleep enuresis, exploding head syndrome, catathrenia or sleep groaning, hypnagogic or hypnopompic hallucinations, sleep-related eating disorders, and parasomnias due to drug, other substance, or medical condition (Table 1 - note not all of the parasomnias are discussed in this article given limited existing literature; American Academy of Sleep Medicine, 2005). Etiologies of the parasomnias vary based upon diagnoses, although some research has suggested correlations between specific parasomnias and psychiatric disorders (Ohayon et al., 1999; Winkelman et al., 1999). This relationship becomes less clear with the realization that some of the medications used to treat psychiatric disorders may themselves be linked to the onset of parasomnias. The literature supports an association between antidepressant pharmacotherapy and certain parasomnias, with the greatest amount of data for RBD (Olson et al., 2000; Winkelman and James, 2004; Teman et al., 2009) and with some data for NREM disorders such as somnambulism and night terrors (Ohayon et al., 1999; Yeh et al., 2009). Reports also link sleep-related eating disorder (Winkelman et al., 1999) to antidepressant use. This review will focus on the association and proposed mechanisms of action of selective serotonin reuptake inhibitors (SSRIs), the serotonin-norepinephrine reuptake inhibitors (SNRIs), the tricyclic antidepressants (TCAs), and the norepinephrine-dopamine reuptake inhibitor bupropion to parasomnias. Literature for this review was obtained via systematic search in PubMed for articles published on or before August 15, 2010. The terms "antidepressants," "parasomnias," "SSRI," "SNRI," "bupropion," "REM behavior disorder," "nightmares," "somnambulism," "confusional arousals," "sleep terrors," "sleep paralysis," "hypnagogic hallucinations," and "hypnopompic hallucinations" were used. References from relevant articles, as well as from recent reviews of the literature, were also assessed.

The reader will also note that the specific effects of antidepressants on the sleep-related movement disorders are not the focus of this parasomnia-centered review, although there is evidence that specific antidepressants may induce restless legs syndrome and/or periodic limb movements of sleep. A review of the most recent literature on this topic is provided in the references (Hoque and Chesson, 2010).

\section{THE SSRIS \\ DEPRESSION AND SLEEP ARCHITECTURE}

Major depression has been studied by polysomnography, with documentation of decreased sleep continuity, prolonged sleep onset latency, increased wake time after sleep onset, decreased sleep efficiency, decreased total sleep time, early morning awakenings, reductions in slow wave sleep, and REM sleep disturbances (Kupfer et al., 1986; Benca et al., 1992). Reduced REM sleep onset latency, increased REM density, and prolonged time spent in first REM 


\section{Table 1 | ICSD-II parasomnias.}

\section{Disorders of Arousal (From Non-Rapid Eye Movement Sleep)}

1. Confusional arousals

2. Sleepwalking

3. Night terrors

\section{Parasomnias Usually Associated With REM Sleep}

1. REM sleep behavior disorder (including parasomnia overlap disorder and status dissociatus)

2. Recurrent isolated sleep paralysis

3. Nightmare disorder

\section{Other Parasomnias}

1. Sleep-related dissociative disorder

2. Sleep Enuresis

3. Sleep-related groaning (catathrenia)

4. Exploding head syndrome

5. Sleep-related hallucinations

6. Sleep-related eating disorder

7. Parasomnia, unspecified

8. Parasomnia due to drug or substance

9. Parasomnia due to medical condition

International classification of sleep disorders, 2nd edition.

sleep period have been described in depressed patients (Kupfer et al., 1981). Several hypotheses have been proposed, including a relative deficiency in sleep homeostasis (sleep drive) with a shifting forward of the circadian cycle (Borbely and Wirz-Justice, 1982), versus alterations in cholinergic, serotonergic, and noradrenergic neurotransmission typically seen in subjects with mood disorders (Thase, 1998). Further detailing of the causes of sleep changes in mood disorders is beyond the scope of this review, but may be found elsewhere in the literature.

\section{ANTIDEPRESSANTS AND SLEEP ARCHITECTURE Selective serotonin reuptake inhibitors}

Serotonin neurons, originating from the dorsal raphe nucleus, project to the cholinergic laterodorsal and pedunculopontine tegmental areas, inhibiting "REM-on" neurons and therefore, inhibiting REM sleep (McCarley and Hobson, 1975; McCarley et al., 1995). In addition to their tendency to suppress REM sleep, SSRIs have also been implicated in sleep fragmentation (Sharpley and Cowen, 1995). Despite these effects on sleep architecture, SSRI treatment of depression may result in an improvement of sleep symptoms in many patients. Some practitioners opt to add the medication trazodone (which improves sleep efficiency and decreases sleep onset latency) as a counter to some of the undesirable sleep changes that may result from SSRI monotherapy (Van Bemmel et al., 1992). Trazodone is a $5-\mathrm{HT}_{2 \mathrm{~A}}$ receptor antagonist that weakly inhibits the $5-\mathrm{HT}_{2} \mathrm{C}$ receptor; its sedative properties may be due to its potent $\alpha 1$-adrenergic blockage (Asayesh, 1986). Finally, a distinctive effect of the SSRI fluoxetine has been described on the polysomnogram (PSG). The term "Prozac eyes" has been used to describe eye movements occurring during all stages of NREM sleep (Armitage et al., 1995a), although the significance of this alteration in the PSG is unknown. Of note, this effect is not exclusive to fluoxetine and has been reported with other SSRIs, including paroxetine, sertraline, citalopram, and escitalopram (Geyer et al., 2009).

\section{TCAs and SNRIs}

The neurophysiologic effect of REM sleep suppression has been observed with TCAs (Kupfer and Spiker, 1982; Armitage, 1996). TCAs (and SNRIs) act predominantly as serotonin and norepinephrine reuptake inhibitors. As serotonergic agents, they might be expected to affect sleep similar to SSRIs. In addition, norepinephrine, originating from the locus ceruleus, has an inhibitory effect on pontine "REM-on" neurons (Semba, 1993). The TCAs, more so than the SNRIs, also have anticholinergic properties of varying degree and contribute to the reduction of REM sleep on this basis (possibly by reducing the effects of acetylcholine in the basal forebrain during REM sleep). Acetylcholine potentiates REM via activation of "REM-on" cells in the pontine tegmentum (Berger and Riemann, 1993). Further sleep-related effects of the TCAs occur through their antagonism at histamine receptors (primarily $\mathrm{H} 1$ and $\mathrm{H} 2$ ). Central histamine at $\mathrm{H} 1$ and $\mathrm{H} 2$ receptors is wakepromoting, and inactivation has been shown in animal models to result in an increase in NREM sleep (Lin et al., 1988).

\section{Bupropion}

Bupropion may reduce REM less than other antidepressants. Bupropion prolongs REM sleep latency and increases REM density (a measure of the number of eye movements in the period) and activity during the first REM sleep period (Ott et al., 2004). Others have found an increase in overall REM sleep percentage with bupropion (Nofzinger et al., 1995). Bupropion's primary mechanism is thought to be via action as a dopamine reuptake inhibitor, though it also acts as a norepinephrine receptor antagonist (Ascher et al., 1995). Its lack of REM sleep suppression may be due to absence of an effect on serotonin reuptake.

\section{SSRIs AND REM SLEEP-RELATED PARASOMNIAS}

Patients with depression frequently have disturbances in REM sleep. SSRIs are known to suppress REM, but are regularly used to treat depression. Given these facts, it is not surprising that REM sleep-related events including parasomnias may occur in depressed patients being treated with SSRIs. A recent crosssectional study published by Lam et al. (2008) found a higher percentage of RBD in subjects with depressive spectrum disorders who were taking SSRIs. The authors prospectively identified patients with parasomnias using a structured questionnaire, and then confirmed diagnoses via clinical interview and PSG for those with recent active parasomnias. Of the 1235 subjects who completed diagnostic interview, 276 (22.3\%) were positive for somnambulism, sleep-related eating disorder, or sleep-related injury, with the latter including REM-related parasomnia as primary cause of injury ( $66.6 \%$ of the 70 subjects with sleep-related injury). REM-related parasomnias included RBD, nightmares, and mixed REM and NREM parasomnias. Sleep violence was correlated with depressive spectrum disorder $(78.3 \%$ of those with depressive spectrum disorder) but no association was found with bipolar or anxiety spectrum disorders. SSRI use was associated with vivid dream recall and loss of REM atonia on PSG in the psychiatric population studied. Subjects taking SSRIs had increased risk of 
having an active $\mathrm{RBD}$-like disorder $(\mathrm{OR}=3.7,95 \% \mathrm{CI}=1.6-8.7$, $p<0.05)$ and $5 \%$ of those subjects taking SSRIs reported symptoms of RBD. Interestingly, the subjects in this study were younger and included more females than are typically associated with the usual demographic for RBD, leading the authors to suggest that psychotropic-related RBD may present in those without the expected characteristics of old age, male predominance, or association with $\alpha$-synucleinopathy. Further, the authors posited that these psychiatric subjects may have been vulnerable to "recurrent emotionally charged and aggressive dreams" and were perhaps more likely to enact RBD-like behaviors in the face of loss of REM atonia. Future studies may help clarify the relationship between drug-related RBD and typical RBD, including the mechanisms underlying each.

Other authors have found a link between SSRI use and the development of RBD symptoms in subjects without known underlying neurodegenerative disease, though study designs differ, and case reports predominate over higher-level methodologies (Schenck et al., 1992; Winkelman and James, 2004). Teman et al. (2009) performed a retrospective case-control chart review in which 48 idiopathic RBD patients were divided into groups based upon age of onset, then were compared to each other and to controls. Early onset RBD patients had significantly more psychiatric diagnoses $(\mathrm{OR}=17.0)$ and antidepressant use $(\mathrm{OR}=12.0)$ than did controls, while late-onset RBD sufferers had similar increase in psychiatric diagnoses without a significant increase in antidepressant use. There were more females in the early onset group. Similar to Lam et al. (2008) the authors suggested that there may be different clinical RBD profiles relative to psychiatric diagnoses, antidepressant use, and age. This may indicate that antidepressant medications contribute independently to RBD onset, particularly in younger patients. As a result, the clinician who is presented with a case of RBD in a younger, female patient may be alerted to screen for antidepressant medications as a possible etiology. In an earlier study, Schenck et al. (1992) retrospectively reviewed 2650 PSG reports to identify those treated with fluoxetine or TCAs, finding in the data a case of fluoxetine-induced RBD that resolved when the medication was discontinued. In addition, there exists one case report of the SSRI paroxetine associated with RBD at a 30-mg dose (Parish, 2007), though an earlier case series (Yamamoto et al., 2006) found improvement in RBD symptoms from paroxetine in 16 out of 19 participants, with possible REM sleep suppression effects as the causal mechanism cited.

In order to better clarify the relationship between RBD and antidepressant use, Winkelman and James (2004) performed a chart review that compared clinical and PSG data of 15 subjects taking serotonergic antidepressants with 15 subjects in an age-matched control group without a depressive or anxiety disorder that was not taking these medications. The antidepressant group exhibited increased tonic submental electromyogram (EMG) activity during REM sleep compared to controls. The authors hypothesized an effect of serotonin on motor systems at the spinal cord or brainstem as a possible mechanism. As this study was retrospective and the control group patients did not have a depressive or anxiety disorder, it is difficult to separate the effects of SSRIs from the effects of such underlying disorders. For example, the relationship of RBD with the synucleinopathies, including Parkinson's disease, multiple system atrophy, and dementia with Lewy Bodies, leaves open the possibility that psychiatric symptoms may predict a later neurologic disorder, an observation noted by Teman et al. (2009). Teman cites several studies that demonstrate the association between depression and Parkinson's disease (Lieberman, 2006) as well as the correlation between RBD and later identification of neurodegenerative disorders (Schenk et al., 1996, 2003; Olson et al., 2000; Boeve et al., 2003). Literature on antidepressants and RBD are provided in Table 2.

Nightmares are a REM-related parasomnia for which a link to SSRIs has been studied (Table 3). Earlier research demonstrated a relationship between SSRI use and dreaming in general, with some studies finding enhancement of dreams with citalopram (Koponen et al., 1997) and fluoxetine (Markowitz, 1991; Armitage et al., 1995b; Lepkifker et al., 1995). Pace-Schott et al. (2001) examined the dream effects of paroxetine and fluvoxamine in 14 normal subjects who were randomized to one of the drugs during 19 days of a 31-day home-based study. While dream recall frequency was diminished during the treatment period, subjective report of dreams indicated increased intensity of dreams during both treatment and acute discontinuation. The authors acknowledge that this effect seemed to run counter to the wellknown effects of REM sleep suppression by SSRIs, and offer that enhanced brain arousal may be associated with aminergic stimulation. They cite a possible difference in processes involved in dream initiation and the quality and/or maintenance of alreadyoccurring dreams, pointing to research by Nofzinger et al. (1995) which found an increase in phasic REM activity with fluoxetine use. An alternative hypothesis by the authors is that late-night cholinergic rebound after serotonergic REM sleep suppression earlier in the night may result in greater dream intensity being reported. The authors acknowledge that patient reports of worsened nightmares with SSRIs are difficult to study, given the complex relationship of depression-related REM enhancement, drug-related REM sleep suppression, depression-related dream suppression, and recovery-related dream enhancement. Further research is needed to elucidate the mechanisms governing these interrelated systems.

\section{SSRIS AND REM-RELATED PARASOMNIAS: CLINICAL GUIDELINES}

No formal clinical guidelines exist for the use of SSRIs in RBD, though there is mention of an adverse relationship in the Best Practice Guide for the Treatment of RBD published by the Standards of Practice Committee of the AASM (Aurora et al., 2010a). Data supporting SSRIs as a possible cause of secondary RBD is presented, though no guidance on treatment is provided. Paroxetine in particular is mentioned, citing the inconclusive data indicating its potential efficacy in the treatment of RBD. The authors state that there is little support for such use. A recent review (Hoque and Chesson, 2010) of pharmacologically induced or exacerbated RLS, PLMs, and RBD, however, did find strong evidence for drug-induced RBD with the TCA clomipramine, the monoamine oxidase inhibitors (MAOIs) selegiline and phenelzine, and lower levels of evidence for the SSRIs. The authors acknowledged that clinicians might opt to modify treatment given the emergence of RBD with the use of certain medications, including switch to an alternative medication or withdrawal of the medication if prudent. 
Table 2 | Antidepressants and parasomnia: RBD.

\begin{tabular}{|c|c|c|c|c|}
\hline Parasomnia & $\begin{array}{l}\text { Antidepressant } \\
\text { medication(s) }\end{array}$ & Reference & Methods/design & Findings \\
\hline \multirow[t]{7}{*}{ RBD } & $\begin{array}{l}\text { SSRIS/SNRI, fluoxetine, } \\
\text { paroxetine, citalopram, } \\
\text { sertraline, venlafaxine }\end{array}$ & $\begin{array}{l}\text { Winkelman and James } \\
\text { (2004) }\end{array}$ & $\begin{array}{l}\text { Chart review, } n=15 \text { on } \\
\text { SSRIs, } n=15 \text { controls, PSG } \\
\text { data included }\end{array}$ & $\begin{array}{l}\text { Antidepressant group had increase in tonic EMG } \\
\text { during REM compared to controls }\end{array}$ \\
\hline & $\begin{array}{l}\text { SSRIs, TCAs, Mixed } \\
\text { Mechanism, bupropion }\end{array}$ & Teman et al. (2009) & $\begin{array}{l}\text { Retrospective, case-control, } \\
\text { chart review, } 48 \text { idiopathic } \\
\text { RBD patients, compared } \\
\text { with controls }\end{array}$ & $\begin{array}{l}\text { Early onset RBD patients exhibited more psychi- } \\
\text { atric diagnoses }[O R=17.0(3.5-83.4)] \text { and anti- } \\
\text { depressant use [OR-12.0 (2.7-53.3)] than non- } \\
\text { RBD controls }\end{array}$ \\
\hline & SSRIs, TCAs & Olson et al. (2000) & $\begin{array}{l}\text { Retrospective chart review } \\
\text { of } 93 \text { consecutive patients } \\
\text { with RBD }\end{array}$ & $\begin{array}{l}\text { Lack of strong causal relationship between anti- } \\
\text { depressants and RBD, however patient mean } \\
\text { age of RBD onset }=60.9,2 \text { of } 11 \text { on antidepres- } \\
\text { sants developed RBD with use of medication }\end{array}$ \\
\hline & SSRI - fluoxetine & $\begin{array}{l}\text { Schenck et al. (1992), } \\
\text { Nofzinger et al. (1995) }\end{array}$ & $\begin{array}{l}\text { Single case in retrospective } \\
\text { review of } n=2650 \text { PSGs }\end{array}$ & $\begin{array}{l}\text { Fluoxetine-induced RBD resolved with discon- } \\
\text { tinuation of medication }\end{array}$ \\
\hline & SSRI - paroxetine & $\begin{array}{l}\text { Parish (2007), Lam et al. } \\
\text { (2008) }\end{array}$ & Case report & $\begin{array}{l}\text { Paroxetine } 30 \mathrm{mg} \text { was associated with RBD-like } \\
\text { symptoms }\end{array}$ \\
\hline & SSRI - paroxetine & $\begin{array}{l}\text { Yamamoto et al. (2006), } \\
\text { Schenck et al. (1992) }\end{array}$ & Case series; $n=19$ & $\begin{array}{l}\text { Paroxetine improved RBD symptoms in 16/19 } \\
\text { studied }\end{array}$ \\
\hline & SSRIs, TCAs, MAOls & $\begin{array}{l}\text { Hoque and Chesson } \\
\text { (2010), Markowitz (1991) }\end{array}$ & Review & $\begin{array}{l}\text { Higher-level of evidence for TCA- and MAOI- } \\
\text { related RBD than SSRIs }\end{array}$ \\
\hline
\end{tabular}

Table 3 | Antidepressants and parasomnia: nightmares.

\begin{tabular}{|c|c|c|c|c|}
\hline Parasomnia & $\begin{array}{l}\text { Antidepressant } \\
\text { medication(s) }\end{array}$ & Reference & Methods/design & Findings \\
\hline Nightmares & Fluoxetine & $\begin{array}{l}\text { Lepkifker et al. (1995), } \\
\text { Schenk et al. (2003) }\end{array}$ & Case series & $\begin{array}{l}\text { Four patients experienced nightmares on fluoxetine } \\
\text { monotherapy }\end{array}$ \\
\hline Nightmares & Bupropion & $\begin{array}{l}\text { Balon (1996), Gaillard } \\
\text { et al. (1994) }\end{array}$ & Case report & $\begin{array}{l}\text { 55-year-old female with nightmares following increase } \\
\text { in bupropion from } 75 \text { to } 150 \mathrm{mg} / \text { day }\end{array}$ \\
\hline $\begin{array}{l}\text { Dream } \\
\text { intensity }\end{array}$ & $\begin{array}{l}\text { Fluoxetine, } \\
\text { paroxetine }\end{array}$ & $\begin{array}{l}\text { Pace-Schott et al. (2001), } \\
\text { Armitage et al. (1995b) }\end{array}$ & $\begin{array}{l}14 \text { Normal subjects randomized } \\
\text { to fluoxetine or paroxetine }\end{array}$ & $\begin{array}{l}\text { Subjects reported increase in dream intensity during } \\
\text { SSRI phase }\end{array}$ \\
\hline $\begin{array}{l}\text { Dream } \\
\text { enhancement }\end{array}$ & Citalopram & $\begin{array}{l}\text { Koponen et al. (1997), } \\
\text { Boeve et al. (2003) }\end{array}$ & Open pilot study & Dream enhancement in $6 \%$ of subjects \\
\hline
\end{tabular}

Careful assessment of the risks and benefits of such a move should occur given the individualized experience of each patient.

Recently, the AASM standards of practice committee published its Best Practice Guide for the Treatment of Nightmare Disorder in Adults (Aurora et al., 2010b). These recommendations indicate that non-SSRI medications such as trazodone, fluvoxamine, and the TCAs "may be considered for treatment of PTSD-associated nightmares, but the data are low grade and sparse." Nefazodone is also mentioned, but not recommended, due to potential for hepatotoxicity. The authors also cite research studying the effect of the SNRI venlafaxine on PTSD-related nightmares, noting no significant difference between the medication and placebo. As a result, venlafaxine is not suggested for the treatment of PTSD-associated nightmares.

\section{REM-RELATED PARASOMNIAS: OTHER ANTIDEPRESSANTS}

Most non-SSRI antidepressants have not been extensively researched for their role in the genesis of REM-related parasomnias. As discussed earlier, those with aminergic properties, such as the SNRIs, have been thought to behave similarly to SSRIs due to their inhibitory effect on REM-on neurons in the pons. The reader is referred to Gaillard et al. (1994) for a further discussion of this mechanism. As discussed, the TCAs, which have aminergic properties, have been implicated for their potential to induce RBD (Mahowald et al., 2007). Anticholinergic effects of the TCAs may be responsible for reduced cholinergic atonia in REM sleep (Schenck et al., 1992). Research detailing the effects of specific SNRIs or bupropion on REM-related parasomnias, however, is lacking. In the Teman et al. (2009) study discussed 
earlier, one of the early onset RBD subjects studied was taking a combination of amitriptyline and paroxetine, and in three others, bupropion was given in combination with another antidepressant. None of the subjects in the late-onset RBD group was taking bupropion. This data is obviously limited, however, and no conclusions about the medications and RBD can be made. There is one case report of bupropion inducing nightmares, with cessation of the nightmares once the medication was discontinued (Balon, 1996). In total, though, there is not a preponderance of literature describing this phenomena in subjects using bupropion.

\section{DEPRESSION AND NREM SLEEP PARASOMNIAS}

The NREM parasomnias are disorders of arousal from NREM sleep, with impaired sleep-wake transitions that can result in activation of physiologic systems. Somnambulism, confusional arousals, and sleep terrors may occur when the transition from slow wave sleep to wakefulness is disrupted. Research has described several factors that may contribute to the development of a NREM parasomnia, including genetic susceptibility, sleep deprivation, situational stress, psychiatric conditions, medication, and substance use (Pressman, 2007). NREM sleep abnormalities have been studied in depressed subjects, with an early study by Buysse et al. (1997) finding a shift in slow wave delta activity to the initial part of the sleep period in depressed subjects following treatment with interpersonal psychotherapy. Subjects who experienced a recurrence of depression exhibited less baseline slow wave activity compared to those still in remission at 1 year follow-up. These findings suggest that depressed patients may themselves be predisposed to NREM sleep disturbance both pre- and mid-treatment Lopes et al. (2007). performed further research into the nature of NREM sleep disturbance in depressed subjects, using analysis of cyclic alternating pattern (CAP) as a measure of NREM variability. The PSGs of 15 subjects with major depressive disorder were compared to those of 20 controls. Researchers found depressives had greater disturbances in phase A1 of CAP, a period of NREM sleep that may indicate an impending shift from NREM stage 2 to NREM stage 3 sleep. This study represents one of the first attempts to clarify the nature of specific NREM sleep disturbance in depressed subjects, and may point to a relationship between somnambulism, which tends to occur in the first third of the night during the greatest period of slow wave sleep, and NREM sleep abnormalities in depressives.

\section{ANTIDEPRESSANTS AND NREM PARASOMNIAS}

There are numerous case reports linking specific antidepressants to the various NREM sleep parasomnias, including reports of somnambulism with bupropion (Khazaal et al., 2003; Oulis et al., 2010), the noradrenergic and specific serotonergic tetracyclic mirtazapine (Yeh et al., 2009), paroxetine (Kawashima and Yamada, 2003), and the norepinephrine reuptake inhibitor reboxetine (Künzel et al., 2004). In contrast, there is one case report detailing the successful treatment of somnambulism and night terrors with paroxetine (Lillywhite et al., 1994), and an earlier report demonstrating efficacy from the tricyclic imipramine (in combination with diazepam) in the treatment of somnambulism and night terrors (Cooper, 1987). In the Lam et al. (2008) study mentioned previously, sedative antidepressants were being used by $34.5 \%$ of the 29 psychiatric subjects who were diagnosed with somnambulism $(p<0.05)$. In their study, "sedative antidepressants" included TCAs, trazodone, and the tetracyclic mianserin. SSRIs, SNRIs, and noradrenergic and specific serotonergic antidepressants were also used in those with somnambulism, but without statistical significance. The authors noted that while the TCAs in particular are not noted for alterations in NREM sleep, their antihistamine and anticholinergic effects might negatively impact arousal. Though the topic is not within the scope of this article, it can be briefly mentioned that Lam et al. (2008) also found increased sleepwalking in those using non-benzodiazepine hypnotics such as zolpidem and zopiclone, medications thought to alter slow wave sleep and possibly leading to arousal disturbances in NREM sleep due to this property. The literature regarding antidepressants and NREM sleep parasomnia is summarized in Table 4.

In summary, the literature concerning NREM sleep parasomnias and antidepressants is limited, with a number of case reports that do not as of yet demonstrate a compelling pattern linking the medications used to treat depression with these sleep disorders. Some of the medications may, in fact, be helpful in the treatment of NREM parasomnias, though there are no large randomized controlled studies to support this. NREM sleep parasomnias may be related to the underlying psychiatric condition, with depression having been studied for NREM abnormalities that may predispose one to dysfunctional transitions between sleep and wake, particularly in the early part of the sleep period. Future investigations might utilize CAP analysis to better describe the specific NREM abnormalities present in depressed subjects, and determine what pharmacologic interventions may target these abnormalities.

\section{ANTIDEPRESSANTS AND OTHER PARASOMNIAS}

The third category of parasomnias, classified as "other parasomnias," includes sleep-related dissociative disorder, sleep enuresis, exploding head syndrome, catathrenia or sleep groaning, hypnagogic or hypnopompic hallucinations, sleep-related eating disorders, and parasomnias due to drug, other substance, or medical condition. Of these, sleep-related eating disorder may have a relationship to depression in that depressives are frequently treated with non-benzodiazepines such as zolpidem for insomnia, and these medications may result in an increase in complex sleeprelated behaviors. Zolpidem has also been studied for its relationship to somnambulism and sleep driving (Hoque and Chesson, 2009). Hwang et al. (2010) studied 125 psychiatric outpatients taking hypnosedatives, and found that $15.2 \%$ reported complex sleep-related behaviors (including sleep-related eating). Of these, all were taking zolpidem, and there was a tendency toward younger age $(p=0.023)$, female gender $(p=0.011)$, and use of higher dose of zolpidem $(>10 \mathrm{mg} /$ day; $p<0.001)$. Sleep-related eating disorder must be distinguished from nocturnal eating syndrome, a disorder typified by a circadian delay in the timing of eating that can be effectively treated with the SSRI sertraline (Stunkard et al., 2006). In sleep-related eating disorder, the patient may not be fully awake during eating, and may have little or no recall for the event the next day. 
Table 4 | Antidepressants and NREM parasomnias.

\begin{tabular}{|c|c|c|c|c|}
\hline Parasomnia & $\begin{array}{l}\text { Antidepressant } \\
\text { medication(s) }\end{array}$ & Reference & Methods/design & Findings \\
\hline Somnambulism & Mirtazapine & Yeh et al. (2009) & Case report & $\begin{array}{l}\text { 40-year-old female with new-onset somnambu- } \\
\text { lism } \times \text { three nights with increase in mirtazapine } \\
\text { from } 30 \text { to } 45 \mathrm{mg} \text {; somnambulism terminated } \\
\text { with cessation of medication }\end{array}$ \\
\hline Somnambulism & Bupropion & $\begin{array}{l}\text { Oulis et al. (2010), } \\
\text { Buysse et al. (1997) }\end{array}$ & Case report & $\begin{array}{l}63 \text {-year-old female with somnambulism in con- } \\
\text { text of adjunctive bupropion for depression }\end{array}$ \\
\hline Somnambulism & Bupropion & $\begin{array}{l}\text { Khazaal et al. (2003), } \\
\text { Lopes et al. (2007) }\end{array}$ & Case report & $\begin{array}{l}\text { 33-year-old male using bupropion } 150 \text { mg BID } \\
\text { for smoking cessation; developed somnam- } \\
\text { bulism and sleep-related eating with use - } \\
\text { resolved with discontinuation }\end{array}$ \\
\hline Somnambulism & Paroxetine & $\begin{array}{l}\text { Kawashima and Yamada } \\
\text { (2003), Oulis et al. (2010) }\end{array}$ & Case report & $\begin{array}{l}61 \text {-year-old female with somnambulism onset } \\
1 \text { week after initiation of paroxetine } 20 \mathrm{mg} \text {; } \\
\text { ceased with discontinuation }\end{array}$ \\
\hline $\begin{array}{l}\text { Somnambulism } \\
\text { night terrors }\end{array}$ & Paroxetine & $\begin{array}{l}\text { Lillywhite et al. (1994), } \\
\text { Kawashima and Yamada } \\
\text { (2003) }\end{array}$ & Case report & $\begin{array}{l}\text { 46-year-old female with somnambulism and } \\
\text { night terrors successfully treated with paroxe- } \\
\text { tine } 40 \mathrm{mg}\end{array}$ \\
\hline Somnambulism & Reboxetine (SNRI) & $\begin{array}{l}\text { Künzel et al. (2004), } \\
\text { Khazaal et al. (2003) }\end{array}$ & Case report & $\begin{array}{l}\text { 19-year-old female with depression and history } \\
\text { of somnambulism in childhood had recurrence } \\
\text { with use of reboxetine }\end{array}$ \\
\hline Somnambulism & $\begin{array}{l}\text { "Sedative } \\
\text { antidepressants," } \\
\text { TCAs, trazodone, } \\
\text { tetracyclic, mianserin }\end{array}$ & $\begin{array}{l}\text { Lam et al. (2008), Ott } \\
\text { et al. (2004) }\end{array}$ & $\begin{array}{l}\text { Prospective, cross-sectional } \\
\text { study, } n=1235 \text { psychiatric } \\
\text { outpatients; questionnaire, } \\
\text { structured interview, PSG }\end{array}$ & $\begin{array}{l}\text { Sedative antidepressants being used by } \\
34.5 \% \text { of the } 29 \text { patients with somnambulism } \\
(p<0.05)\end{array}$ \\
\hline
\end{tabular}

Table 5 | Antidepressants and other parasomnias.

\begin{tabular}{|c|c|c|c|c|}
\hline Parasomnia & $\begin{array}{l}\text { Antidepressant } \\
\text { medication(s) }\end{array}$ & Reference & Methods/design & Findings \\
\hline $\begin{array}{l}\text { Sleep-related } \\
\text { eating disorder }\end{array}$ & Unknown & Winkelman et al. (1999) & $\begin{array}{l}n=207 \text { depressed subjects in } \\
\text { antidepressant trial were } \\
\text { administered. The inventory of } \\
\text { nocturnal eating }\end{array}$ & $\begin{array}{l}3.4 \% \text { of depressed subjects reported symp- } \\
\text { toms of sleep-related eating disorder, thought } \\
\text { to be higher prevalence than that in general } \\
\text { population }\end{array}$ \\
\hline $\begin{array}{l}\text { Hypnagogic/ } \\
\text { hypnopompic } \\
\text { hallucinations }\end{array}$ & Unknown & $\begin{array}{l}\text { Ohayon et al. (1996), } \\
\text { Hwang et al. (2010) }\end{array}$ & $\begin{array}{l}n=4972 \text { U.K. community sample } \\
\text { interviewed by telephone about } \\
\text { sleep disturbances }\end{array}$ & $\begin{array}{l}\text { Increase in hypnopompic hallucinations in sub- } \\
\text { jects taking antidepressants }[\mathrm{OR}=1.4(95 \% \mathrm{Cl} \\
1-1.9)]\end{array}$ \\
\hline
\end{tabular}

Hypnagogic or hypnopompic hallucinations occur at sleep onset or awakening and may be associated with psychiatric disorders. In research by Ohayon et al. (1996) these phenomena were found to occur more frequently than predicted by the prevalence of narcolepsy, a diagnosis with which hypnagogic and hypnopompic hallucinations are associated. A community sample of 4972 subjects underwent a telephone interview that involved demographic questioning as well as diagnostic analysis of sleep disorders. The subjects were also asked about sleep habits as well as the presence of psychiatric disorders and the symptoms associated with them. Subjects with anxiety disorders and depression reported a statistically significant higher rate of sleep-related hallucinations (hypnagogic: anxiety disorder $\mathrm{OR}=1.4,95 \%$ CI 1.3-1.8; mood disorder OR 1.52, 95\% CI 1.2-1.8 and hypnopompic: anxiety disorder OR 1.4, 95\% CI
1.1-1.8, mood disorder OR 1.52, 95\% CI 1.2-1.8). Of note, the authors failed to find an association between the presence of these hallucinations and the use of any psychotropic medications in the subjects reporting hypnagogic hallucinations, but use of sleep-inducing, anxiolytic, or antidepressant medication did predict an increase in hypnopompic hallucinations $(\mathrm{OR}=1.4$, 95\% CI 1.0-1.9). However, as the specific medications used are not reported in the article, it is difficult to reach meaningful conclusions regarding antidepressant use and sleep-related hallucinations. Careful diagnosis is essential, as hallucinations may be related to RBD, narcolepsy, or other neurologic or psychiatric disorder, any of which may have their own propensity to emerge in the presence of various medications. The literature regarding antidepressants and other parasomnias is summarized in Table 5. 


\section{CONCLUSION}

There exists a varying level of evidence linking the use of antidepressant medication to the parasomnias, ranging from larger, more comprehensive studies in the area of RBD to primarily case reports in the NREM parasomnias. As such, practice guidelines are lacking regarding specific direction to the clinician who may be faced with a patient who has developed a parasomnia that appears to be temporally related to use of an antidepressant. In general, knowledge of the mechanisms of action of the medications, particularly with regard to the impact on sleep architecture, can provide some guidance. There is a potential for SSRIs,
TCAs, and SNRIs to suppress REM, as well as the anticholinergic properties of the individual drugs to further disturb normal sleep architecture.

New research may suggest patterns of NREM disturbances associated with depression and the medications used to treat depression. These abnormalities may result in a disturbance of the stability of NREM sleep that may predispose to one or more parasomnias. Understanding the mechanisms that govern the action of these medications, as well as the pathogenesis of depression itself, will provide further guidance into the relationship of antidepressant use and the parasomnias.

\section{REFERENCES}

American Academy of Sleep Medicine. (2005). International Classification of Sleep Disorders. Diagnostic and Coding Manual, 2nd Edn. Westchester, IL: American Academy of Sleep Medicine.

Armitage, R. (1996). Effects of antidepressant treatment on sleep EEG in depression. J. Psychopharmacol. (Oxford) 10, S22-S25.

Armitage, R., Trivedi, M., and Rush, A. J. (1995a). Fluoxetine and oculomotor activity during sleep in depressed patients. Neuropsychopharmacology 12, 159-165.

Armitage, R., Rochlen, A., Fitch, T., Trivedi, M., and Rush, J. (1995b). Dream recall and major depression: a preliminary report. Dreaming 5, 189-198.

Asayesh, K. (1986). Combination of trazodone and phenothiazines: a possible additive hypotensive effect. Can. J. Psychiatry 31, 857-858.

Ascher, J. A., Cole, J. O., Colin, J. N., Feighner, J. P., Ferris, R. M., Fibiger, H. C., Golden, R. N., Martin, P., Potter, W. Z., and Richelson, E. (1995). Bupropion: a review of its mechanism of antidepressant activity. $J$. Clin. Psychiatry 56, 395-401.

Aurora, R. N., Zak, R. S., Maganti, R. K., Auerbach, S. H., Casey, K. R., Chowdhuri, S., Karippot, A., Ramar, K., Kristo, D. A., and Morgenthaler, T. I. (2010a). Best practice guide for the treatment of REM sleep behavior disorder (RBD). J. Clin. Sleep Med. 6, 85-95.

Aurora, R. N., Zak, R. S., Auerbach, S. H., Casey, K. R., Chowdhuri, S., Karippot, A., Maganti, R. K., Ramar, K., Kristo, D. A., Bista, S. R., Lamm, C. I., and Morgenthaler, T. I. (2010b). Best practice guide for the treatment of nightmare disorder in adults. J. Clin. Sleep Med. 6, 389-401.

Balon, R. (1996). Bupropion and nightmares. Am. J. Psychiatry 153, 579-580.

Benca, R. M., Obermeyer, W. H., Thisted, R. A., and Gillin, J. C.
(1992). Sleep and psychiatric disorders: a meta-analysis. Arch. Gen. Psychiatry 49, 651-668.

Berger, M., and Riemann, D. (1993). REM sleep in depression - an overview. J. Sleep Res. 2, 211-223.

Boeve, B., Silber, M., Parisi, J., Dickson, D. W., Ferman, T. J., Benarroch, E. E., Schmeichel, A. M., Smith, G. E., Petersen, R. C., Ahlskog, J. E., Matsumoto, J. Y., Knopman, D. S., Schenck, C. H., and Mahowald, M. W. (2003). Synucleinopathy pathology and REM sleep behavior disorder plus dementia or Parkinsonism. Neurology 61, 40-45.

Borbely, A., and Wirz-Justice, A. (1982). Sleep, sleep deprivation, and depression: a hypothesis derived from a model of sleep regulation. Hum. Neurobiol. 1, 205-210.

Buysse, D. J., Frank, E., Lowe, K. K., Cherry, C. R., and Kupfer, D. J. (1997). Electroencephalographic sleep correlates of episode and vulnerability to recurrence in depression. Biol. Psychiatry 41, 406-418.

Cooper, A. J. (1987). Treatment of coexistent night terrors and somnambulism in adults with imipramine and diazepam. J. Clin. Psychiatry 48, 209-210.

Gaillard, J. M., Nicholson, A. N., and Pascoe, P. A. (1994). "Neurotransmitter systems," in Principles and Practice of Sleep Medicine, 2nd Edn, eds M. Kryger, T. Roth, and W. Dement (Philadelphia, PA: W. B. Saunders), 338-348.

Geyer, J. D., Carney, P. R., Dillard, S. C., Davis, L., and Ward, L. C. (2009). Antidepressant medications, neuroleptics, and prominent eye movements during NREM sleep. J. Clin. Neurophysiol. 26, 39-44.

Hoque, R., and Chesson, A. L. Jr. (2009). Zolpidem-induced sleepwalking, sleep related eating disorder, and sleep driving: fluorine-18fluorodeoxyglucose positron emission tomography analysis, and a literature review of other unexpected clinical effects of zolpidem. J. Clin. Sleep. Med. 5, 471-476.

Hoque, R., and Chesson, A. L. (2010). Pharmacologically induced/exacerbated restless legs syndrome, periodic limb movements of sleep, and REM behavior disorder/REM sleep without atonia: literature review, qualitative scoring, and comparative analysis. J. Clin. Sleep Med. 6, 79-83.

Hwang, T. J., Ni, H. C., Chen, H. C. Lin, Y. T., and Liao, S. C. (2010). Risk predictors for hypnosedative-related complex sleep behaviors; a retrospective, cross-sectional pilot study. J. Clin. Psychiatry 71, 1331-1335.

Kawashima, T., and Yamada, S. (2003). Paroxetine-induced somnambulism. J. Clin. Psychiatry 64, 483.

Khazaal, Y., Krenz, S., and Zullino, D. F. (2003). Bupropion-induced somnambulism. Addict. Biol. 8, 359-362.

Koponen, H., Leopla, U., Leiononen, E. Jokinen, R., Penttinen, J., and Turtonen, J. (1997). Citalopram in the treatment of obsessive-compulsive disorder: an open pilot study. Acto Psychiatr. Scand. 96, 343-346.

Künzel, H. E., Schuld, A., and Pollmächer, T. (2004). Sleepwalking associated with reboxetine in a young female patient with major depression - a case report. Pharmacopsychiatry 37, 307-308.

Kupfer, D. J., Gillin, J. C., Coble, P. A. Spiker, D. G., Shaw, D., and Holzer, B. (1981). REM sleep, naps, and depression. Psychiatry Res 5, 195-203.

Kupfer, D. J., Reynolds, C. F. III, Ulrich, R. D., and Grochocinski, V. J. (1986). Comparison of automated REM and slow-wave sleep analysis in young and middle-aged depressed subjects. Biol. Psychiatry 21, 189-200.

Kupfer, D. J., and Spiker, D. G. (1982). Nortriptyline and EEG sleep in depressed patients. Biol. Psychiatry 17, 535-546.

Lam, S. P., Fong, S. Y., Ho, C. K., Yu, M. W., and Wing, Y. K.
(2008). Parasomnia among psychiatric outpatients: clinical, epidemiologic, cross-sectional study. J. Clin. Psychiatry 69, 1374-1382.

Lepkifker, E., Dannon, P. N., Iancu, I., Ziv, R., and Kotler, M. (1995). Nightmares related to fluoxetine treatment. Clin. Neuropharmacol. 18, 90-94.

Lieberman, A. (2006). Depression in Parkinson's disease - a review. Acta Neurol. Scand. 113, 1-8.

Lillywhite, A. R., Wilson, S. J., and Nutt, D. J. (1994). Successful treatment of night terrors and somnambulism with paroxetine. Br. J. Psychiatry 164, 551-554.

Lin, J. S., Sakai, K., and Jouvet, M. (1988). Evidence for histaminergic arousal mechanisms in the hypothalamus of the cat. Neuropharmacology 27, 111-122.

Lopes, M., Quera-Salva, M. A., and Guilleminault, C. (2007). Non-REM sleep instability in patients with major depressive disorder: subjective improvement and improvement of non-REM sleep instability with treatment (agomelatine). Sleep Med. 9, 33-41.

Mahowald, M. W., Schenck, C. H., and Bornemann, M. A. (2007). Pathophysiologic mechanisms in REM sleep behavior disorder. Curr. Neurol. Neurosci. Rep. 7, 167-172.

Markowitz, J. (1991). Fluoxetine and dreaming. J. Clin. Psychiatry 52, 432.

McCarley, R. W., Greene, R. W., Rainnie, D., and Portas, C. M. (1995). Brainstem neuromodulation and REM sleep. Semin. Neurosci. 7, 341-354.

McCarley, R. W., and Hobson, J. A. (1975). Neuronal excitability modulation over the sleep cycle: a structural and mathematical model. Science 189, 58-60.

Nofzinger, E. A., Reynolds, C. F. III, Thase, M. E., Frank, E., Jennings, J. R., Fasiczka, A. L., Sullivan, L. R., and Kupfer, D. J. (1995). REM sleep enhancement by bupropion in depressed men. Am. J. Psychiatry $152,274-276$. 
Ohayon, M. M., Guilleminault, C., and Priest, R. G. (1999). Night terrors, sleepwalking, and confusional arousals in the general population: their frequency and relationship to other sleep and mental disorders. J. Clin. Psychiatry 60, 268-276.

Ohayon, M. M., Priest, R. G., Caulet, M., and Guilleminault, C. (1996). Hypnagogic and hypnopompic hallucinations: pathological phenomena? $\mathrm{Br}$. J. Psychiatry 169, 459-467.

Olson, E., Boeve, B., and Silber, M. (2000). Rapid eye movement sleep behaviour disorder: demographic, clinical and laboratory findings in 93 cases. Brain 123(Pt 2), 331-339.

Ott, G. E., Rao, U., Lin, K. M., Gertsik, L., and Poland, R. E. (2004). Effect of treatment with bupropion on EEG sleep: relationship to antidepressant response. Int. J. Neuropsychopharmacol. 7, 275-281.

Oulis, P., Kokras, N., Papadimitriou, G. N., and Masdrakis, V. G. (2010). Bupropion-induced sleepwalking. J. Clin. Psychopharmacol. 30, 83-84.

Pace-Schott, E. F., Gersh, T., Silvestri, R., Stickgold, R., Salzman, C., and Hobson, J. A. (2001). SSRI treatment suppresses dream recall frequency but increases subjective dream intensity in normal subjects. J. Sleep Res. 10, 129-142.

Parish, J. M. (2007). Violent dreaming and antidepressant drugs: or how paroxetine made me dream that I was fighting Saddam Hussein. J. Clin. Sleep. Med. 3, 529-531.
Pressman, M. R. (2007). Factors that predispose, prime, and precipitate NREM parasomnias in adults: clinical and forensic implications. Sleep Med. Rev. 11, 5-30.

Schenck, C., Mahowald, M., Kim, S., O'Connor, K. A., and Hurwitz, T. D. (1992). Prominent eye movements during NREM sleep and REM sleep behavior disorder associated with fluoxetine treatment of depression and obsessive-compulsive disorder. Sleep 15, 226-235.

Schenk, C., Bundlie, S., and Mahowald, M. (1996). Delayed emergence of a Parkinsonian disorder in $38 \%$ of 29 older men initially diagnosed with idiopathic rapid eye movement sleep behaviour disorder. Neurology 46, 388-393.

Schenk, C., Bundlie, S., and Mahowald, M. (2003). REM behavior disorder: delayed emergence of Parkinsonism and/or dementia in $65 \%$ of older men initially diagnosed with idiopathic rbd, and an analysis of the minimum and maximum tonic and/or phasic electromyographic abnormalities found during REM sleep. Sleep 26(Suppl.), A316.

Semba, K. (1993). Aminergic and cholinergic afferents to REM sleep induction regions of the pontine reticular formation in the rat. $J$. Comp. Neurol. 330, 543-546.

Sharpley, A. L., and Cowen, P. J. (1995). Effect of pharmacological treatments of depressed patients. Biol. Psychiatry 37, 85-98.
Stunkard, A. J., Allison, K. C., Lundgren, J. D., Martino, N. S., Heo, M., Etemad, B., and O'Reardon, J. P. (2006). A paradigm for facilitating pharmacotherapy at a distance: sertraline treatment of the night eating syndrome. J. Clin. Psychiatry 67, 1568-1572.

Teman, P. T., Tippmann-Peikert, M. Silber, M. H., Slocumb, N. L., and Auger, R. R. (2009). Idiopathic rapid-eye-movement sleep disorder: associations with antidepressants, psychiatric diagnoses, and other factors, in relation to age of onset. Sleep Med. 10, 60-65.

Thase, M. E. (1998). Depression, sleep, and antidepressants. J. Clin. Psychiatry 59, S55-S65.

Van Bemmel, A. L., Havermans, R. G., and van Diest, R. (1992) Effects of trazodone on EEG sleep and clinical state in major depression. Psychopharmacology (Berl.) 107, 569-574.

Winkelman, J., and James, L. (2004). Serotonergic antidepressants are associated with REM sleep without atonia. Sleep 27, 317-321.

Winkelman, J. W., Herzog, D. B., and Fava, M. (1999). The prevalence of sleep-related eating disorder in psychiatric and non-psychiatric populations. Psychol. Med. 29, 1461-1466.

Yamamoto, K., Uchimura, N. Habukawa, M., Takeuchi, N., Oshima, H., Oshima, M., and
Maeda, H. (2006). Evaluation of the effects of paroxetine in the treatment of REM sleep behavior disorder. Sleep Biol. Rhythms 4, 190-192.

Yeh, Y, Chen, C., Feng, H., Wang, S. C., Kuo, S. C., and Chen, C. K. (2009). New onset somnambulism associated with different dosage of mirtazapine: a case report. Clin. Neuropharmacol. 32, 232-233.

Conflict of Interest Statement: The authors declare that the research was conducted in the absence of any commercial or financial relationships that could be construed as a potential conflict of interest.

Received: 26 August 2010; accepted: 22 November 2011; published online: 12 December 2011.

Citation: Kierlin $L$ and Littner $M R$ (2011) Parasomnias and antidepressant therapy: a review of the literature. Front. Psychiatry 2:71. doi: 10.3389/fpsyt.2011.00071

This article was submitted to Frontiers in Sleep Disorders, a specialty of Frontiers in Psychiatry.

Copyright (c) 2011 Kierlin and Littner. This is an open-access article distributed under the terms of the Creative Commons Attribution Non Commercial License, which permits non-commercial use, distribution, and reproduction in other forums, provided the original authors and source are credited. 